Proc. Indian Acad. Sci. (Earth Planet. Sci.), Vol. 105, No. 3, September 1996, pp. 343-355.

(C) Printed in India.

\title{
Statistical analysis of the position of the monsoon trough
}

\author{
G RAJKUMAR and R NARASIMHA* \\ Jawaharlal Nehru Centre for Advanced Scientific Research, Jakkur P.O., Bangalore 560 064, \\ India
}

\begin{abstract}
Using surface charts at $0330 \mathrm{GMT}$, the movement of the monsoon trough during the months June to September 1990 at two fixed longitudes, namely $79^{\circ} \mathrm{E}$ and $85^{\circ} \mathrm{E}$, is studied. The probability distribution of trough position shows that the median, mean and mode occur at progressively more northern latitudes, especially at $85^{\circ} \mathrm{E}$, with a pronounced mode that is close to the northern-most limit reached by the trough. A spectral analysis of the fluctuating latitudinal position of the trough is carried out using FFT and the Maximum Entropy Method (MEM). Both methods show significant peaks around 7.5 and 2.6 days, and a less significant one around 40-50 days. The two peaks at the shorter period are more prominent at the eastern longitude. MEM shows an additional peak around 15 days. A study of the weather systems that occurred during the season shows them to have a duration around 3 days and an interval between systems of around 9 days, suggesting a possible correlation with the dominant short periods observed in the spectrum of trough position.
\end{abstract}

Keywords. Monsoon trough; statistics; spectrum; MONTBLEX.

\section{Introduction}

It is well known that the position and intensity of the monsoon trough have a vital bearing on the monsoon rainfall of India (e.g., Rao 1976; Sikka and Narasimha 1995). In particular, fluctuations in the position of the trough (which can move by as much as $5^{\circ}$ latitude in a day) are related to the short-period variations of rainfall. Thus, when the axis of the trough moves north and lies close to the Himalaya, rainfall weakens over most of north India (a condition characteristic of the so-called break in the monsoons, although widespread and heavy rains occur in the northeast, the Himalayan foothills and the southeast peninsula); correspondingly when the trough moves south there tends to be heavy rains in the north Indian plains and the monsoon becomes 'active' (with the opposite trend in the other areas already mentioned). It is therefore of great interest to study the fluctuations of the monsoon trough.

Rao (1976) quotes studies by Srinivasan and Ramakrishnan (1970) on the position of the trough in July and August. The trough is found to be in the "near-normal" position on only $30-47 \%$ of the occasions, and "more frequently to the north of the mean position" at $77^{\circ} \mathrm{E}$. It is not clear how the "normal" position is defined, as the table accompanying the discussion (Rao 1976, p. 94) shows that, at $77^{\circ} \mathrm{E}$, the trough is more often north of the normal position in both July and August; the "normal" does not coincide with any of the well-known statistical location parameters, like the mean, the median and the mode. A possible explanation is that the normal position is based on monthly averages of the surface pressure (Joseph P. V. 1996,

\footnotetext{
*Also at Centre for Atmospheric Sciences, Indian Institute of Science, Bangalore 560012.
} 


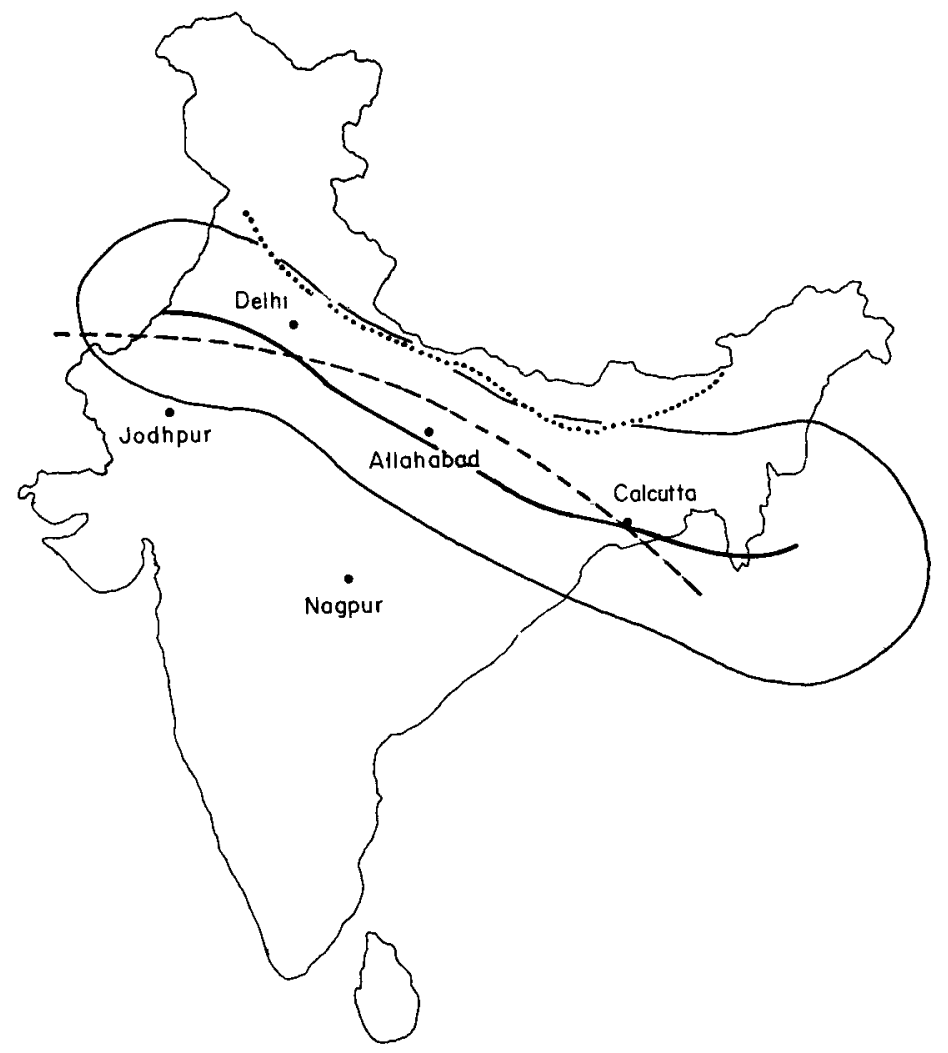

Figure 1. Typical monsoon trough positions during active (dashed line) and weak (dotted line) phases, with region of one standard deviation (enveloping continuous line) around the mean from Paul and Sikka (1976).

private communication) and so weighs the pressures differently from a monthly average of trough position.

Paul and Sikka (1976) analysed the mean and standard deviation in the latitudinal position of the trough at nine longitudes ranging from $73.25^{\circ} \mathrm{E}$ to $93.75^{\circ} \mathrm{E}$. The trough position was determined using both pressure and wind direction data over a period of 20 years (0300 GMT during July and August, 1946-65). The analysis showed that the mean position varied from $28.9^{\circ} \mathrm{N}$ at $73.25^{\circ} \mathrm{E}$ to $21.6^{\circ} \mathrm{N}$ at $93.75^{\circ} \mathrm{E}$ (see figure 1); the standard deviation was nearly constant at about $2.6^{\circ}$ up to about $87^{\circ} \mathrm{E}$, but increased rapidly eastwards to $3.9^{\circ}$ at $93.75^{\circ} \mathrm{E}$.

In their study of the oscillations of the monsoon system, Krishnamurthy and Bhalme (1976) investigated nine characteristic parameters including the mean sea-level pressure over the monsoon trough, with a sample of 92 days covering the months of July, August and September in the year 1967 (which had near-normal rainfall). A spectral analysis was made using the direct FFT technique. The analysis revealed a salient oscillation at a period of about 11.5 days, and another at 4.5 days. From an analysis of the other eight parameters as well, the authors concluded that the monsoon system exhibits a "quasi-bi-weekly" oscillation with a period of $14 \pm 2$ days, and a short-period fluctuation on a scale of 2-6 days. It was suggested that while the latter 
might be a reflection of local instabilities or passage of local disturbances, the quasi-bi-weekly oscillation could be due to winter-hemisphere or planetary scale waves, or a manifestation of a natural cycle in the monsoons involving cloud/radiation/ stability interactions.

The objective of the present note is to provide a brief statistical analysis of the monsoon trough position during the MONTBLEX year 1990, with a view to determining the relevant time scales in its dynamics (and possibly also of the monsoon trough boundary layer). It is proposed to supplement the present analysis by examining data from other years as well.

\section{Determination of the trough position}

In this paper, we determine the trough position as a curve drawn from the seasonal low over the Pakistan area eastward to Gangetic West Bengal, demarcating the regions where the winds have an easterly component to the north from those where they have a westerly component to the south, and taking into account surface pressure. The frequent presence of a low pressure region to the east helps to fix the position of the trough. For the purpose of the present study two longitudes where the trough is almost always well-defined were selected, namely $79^{\circ} \mathrm{E}$ and $85^{\circ} \mathrm{E}$ respectively towards the two ends of the trough. These longitudes are separated by around $660 \mathrm{~km}$. Outside this range the trough is frequently difficult to define and (especially near the Bay) may not even have a unique position; as gaps in the time series may vitiate the spectral analysis we shall describe below, we have limited ourselves to the two selected longitudes. The data on the surface pressure and wind were taken chiefly from the Indian Daily Weather Report. The position so determined is accurate to within about 1 degree latitude at both longitudes.

Except for four days at the eastern end, trough positions at both selected longitudes could be determined unambiguously and objectively on all days from 4th June to 14 th September 1990. On one day (10th August) the eastern end of the trough was difficult to identify, because there were no closed isobars locating a low pressure region and the surface wind did not show the characteristic change in direction. In the present analysis, the position for this day has been taken as the mean of the positions on the previous and on the next day, taking account of the overall wind and pressure patterns. On 17th June and 31 st August, the trough could not be drawn beyond $83^{\circ} \mathrm{E}$ longitude; on 8 th August it could be drawn only up to $82^{\circ} \mathrm{E}$. On these three occasions, the position was determined by extrapolation to $85^{\circ} \mathrm{E}$ longitude. On all other days the trough was clearly defined.

Figure 1 shows the trough position on a typical day (25th August 1990) when it was close to the Himalayan foothills (weak monsoon activity), as well as on another day (1st July 1990) when it was over the central parts of the country with the eastern end dipping into the Bay of Bengal (active monsoon). For comparison, the mean \pm standard deviation position of the trough as found by Paul and Sikka (1976) for July and August (over a 20-year period) is also shown in figure 1; the two data sets are clearly consistent.

The daily position of the trough during June, July and August 1990 has been plotted for both the selected longitudes in figure 2(a,b and c). By and large the fluctuations at the two longitudes appear to be in phase. It will be seen that the position fluctuates from $21 \cdot 4^{\circ} \mathrm{N}$ (17th August) to $32 \cdot 0^{\circ} \mathrm{N}$ (27th August) at $79^{\circ} \mathrm{E}$ longitude, and from $15^{\circ} \mathrm{N}$ 
(8th August) to $27^{\circ} \mathrm{N}\left(25\right.$ th June) at $85^{\circ} \mathrm{E}$ longitude. The extremes in the trough position over land correlate well with the orography: the Himalayan range in the north, and the Satpura-Vindhya ranges in the south.

\section{Probability distributions}

Table 1 lists the mean and standard deviation in the latitude of the trough at both longitudes. The data are in broad agreement with the figures quoted by Paul and Sikka (1976) as averages over a 20-year period, also shown in the same table. The extreme positions generally occur during the month of August, which is consistent with the high standard deviation for that month as can be seen from table 1. Indeed, as figure 2 indicates, the fluctuations in the trough position appear most vigorous in August, which experienced two depressions and three low-pressure areas (Srivastav 1995). Furthermore, during August the trough was significantly southward of its mean position during the [rest of the] season.

The position of the trough, at the two longitudes selected, has been placed in 2-degree (latitude) bins and their frequencies calculated. The resulting probability histograms are shown in figure 3. The distributions reveal a striking skewness: the mode, at both longitudes, is north of the mean; but there is a relatively sharp cut-off northwards of the mode; on the other hand each distribution shows a long southward tail. The mean is not necessarily the best indicator of the location in such cases. Table 2 presents the median, mean, and mode at both longitudes: it will be seen that they occur at respectively more northern latitudes, and that the differences between them are rather larger at the eastern end of the trough.

These data imply that care is needed in describing the location of the trough. Thus, at both longitudes but more markedly at the eastern end, the most probable location is

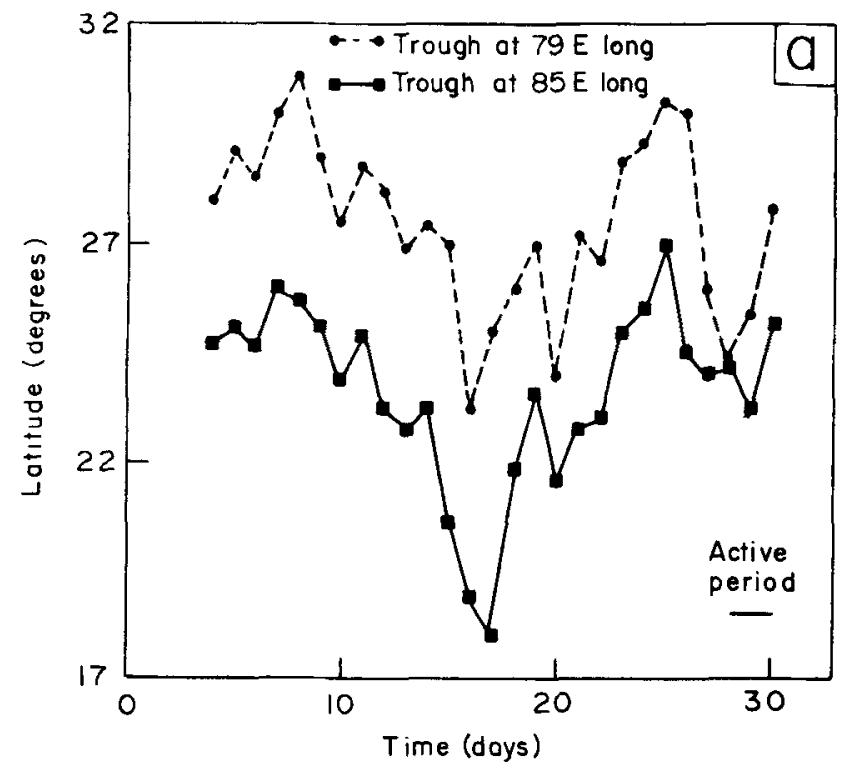

Figure 2(a). Latitudinal positions of the monsoon trough in June 1990. 


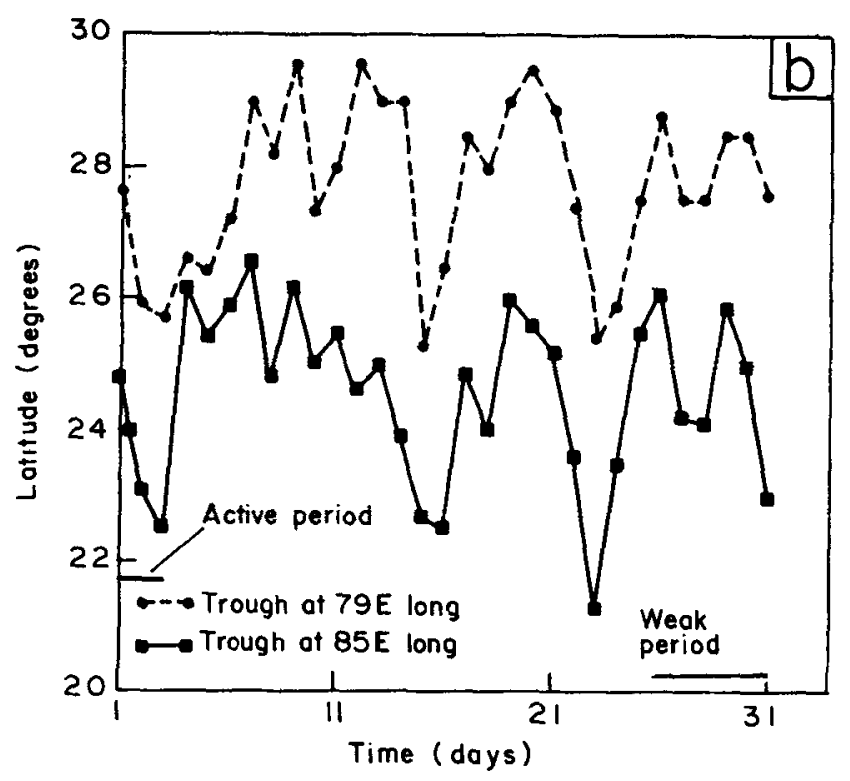

Figure 2(b). Latitudinal positions of the monsoon trough in July 1990.

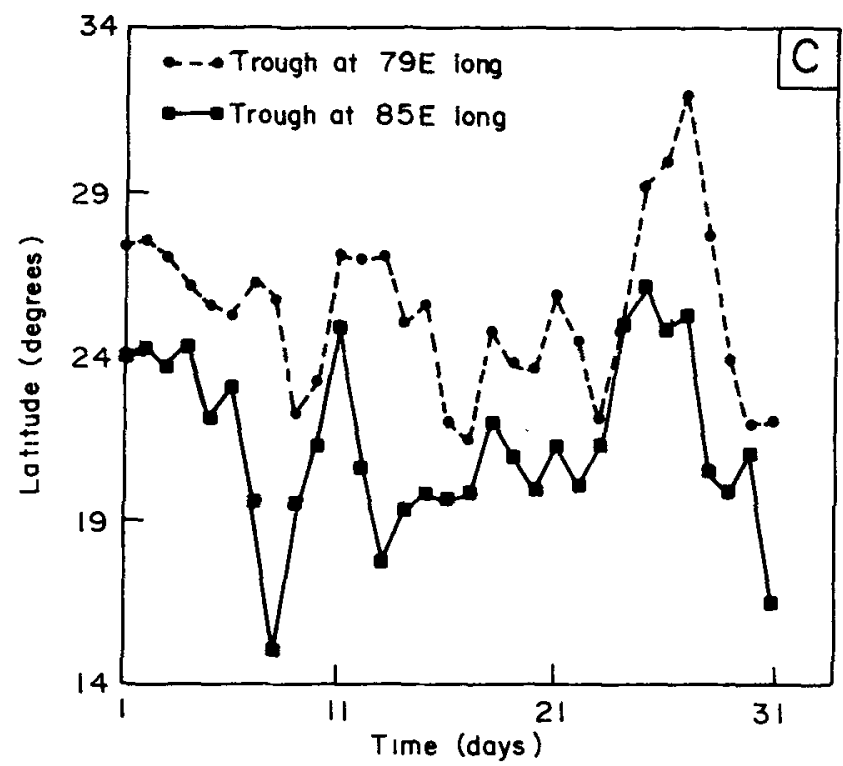

Figure 2(c). Latitudinal positions of the monsoon trough in August 1990.

north of the mean but more than half the time the trough is south of the mean! Another way of putting it is that there is a well-marked, northern-most position that the trough prefers to lock into, although it is away from it for appreciable lengths of time. This is particularly true during July, when the trough is very active and touches its northern limit frequently, as is visually clear from figure 2(b). 
Table 1. Statistical parameters of the position of the monsoon trough.

\begin{tabular}{lllll}
\hline \multirow{2}{*}{ Period } & \multicolumn{2}{c}{ Position at $79^{\circ} \mathrm{E}$} & \multicolumn{2}{c}{ Position at $85^{\circ} \mathrm{E}$} \\
& mean & s.d. & mean & s.d. \\
\hline June & 27.50 & 1.98 & 23.62 & 2.08 \\
July & 27.72 & 1.27 & 24.60 & 1.32 \\
August & 25.39 & 2.52 & 21.37 & 2.66 \\
September & 27.26 & 2.11 & 23.31 & 1.55 \\
Junc-September & 26.9 & 2.22 & 23.20 & 2.38 \\
Paul and Sikka & 26.8 & 2.3 & 23.0 & 2.6 \\
\hline
\end{tabular}

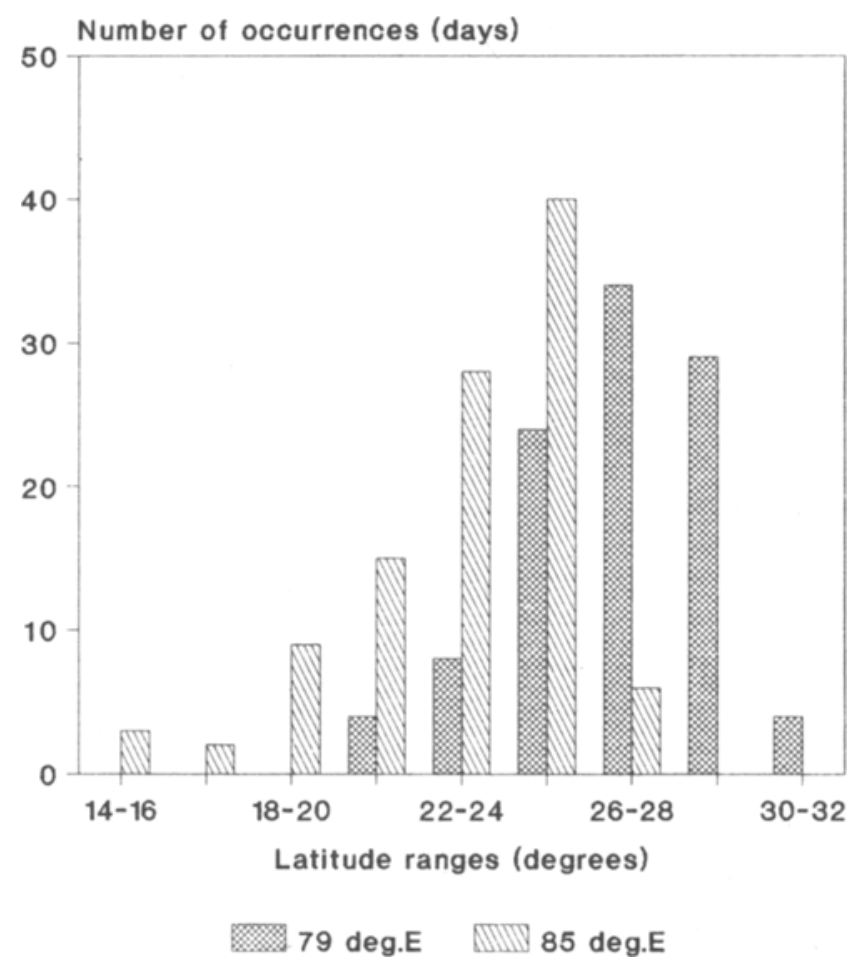

Figure 3. Frequency distribution of the position of the monsoon trough.

\section{Spectra}

It is interesting to study the spectral characteristics of the fluctuations in the position of the trough, based on the time series of latitudinal position shown in figure 2 .

Spectral analysis can be carried out by any of several methods; these have been critically discussed by Press et al (1986) and MacDonald (1989). We adopt here two independent methods.

The first is a simple method following WMO (1966), which is an approach similar to that developed by Blackman and Tukey (1958). In this method, one starts with a given time series of $N$ equally spaced values, and computes all serial covariances for lags from 0 to $m$ time units, where $m$ is some number less than the number of data points $N$. Then 
Table 2. Location of monsoon trough.

\begin{tabular}{lccc}
\hline $\begin{array}{l}\text { Longitude deg. } \\
\text { East }\end{array}$ & $\begin{array}{c}\text { Median deg. } \\
\text { North }\end{array}$ & $\begin{array}{c}\text { Mean deg. } \\
\text { North }\end{array}$ & $\begin{array}{c}\text { Mode deg } \\
\text { North }\end{array}$ \\
\hline 79 & 26.7 & 26.9 & 27.0 \\
85 & 21.0 & 23.2 & 25.0 \\
\hline
\end{tabular}

one computes the cosine transform of the resulting $m+1$ lag covariance values, obtaining raw spectral estimates. These estimates are then smoothed to obtain consistent estimates of the final power spectrum, and evaluated for statistical significance.To do this, we fit a null hypothesis continuum to the spectrum. Assuming $r_{1}$ to be the lag-one correlation coefficient for the population, the following expression is evaluated for various choices of the harmonic number $k$ between 0 and $m$ :

$$
S_{k}=\bar{s}\left[\frac{1-r_{1}^{2}}{1+r_{1}^{2}-2 r_{1} \cos (\pi k / m)}\right] .
$$

Here $\bar{s}$ is the average of all the $m+1$ raw spectral estimates.

Tukey (1950) has found that the ratio of the magnitude of the spectral estimate to the local magnitude of the continuum is distributed as chi-square divided by the degrees of freedom. Thus, given the degrees of freedom, the critical percentage point levels can be found from standard statistical tables. In other words a desired percentage confidence level for the null continuum is given as a second spectrum whose value for any wavelength is equal to a certain fixed multiple of the value of the null continuum at that wavelength. We compute in this way the continuum at 99 and 95 per cent confidence levels and plot them along with spectral estimates.

The spectra using this method are shown in figures 4 and 5 for the time series of trough position at $79^{\circ} \mathrm{E}$ and $85^{\circ} \mathrm{E}$ respectively; the prominent peaks are listed in table 3 . One peak showing a periodicity of 7.7 days is seen clearly, and is significant at better than $99 \%$. At $79^{\circ} \mathrm{E}$ two other peaks at 3.7 and 2.7 days are significant at $95 \%$ whereas at $85^{\circ} \mathrm{E}$ two different peaks at 2.9 and 2.6 days are significant at $99 \%$ and one at 4.5 days above $95 \%$ level. Peaks of the same periodicity viz., 7.7 and 2.7 days are seen at both longitudes, suggesting that they are robust characteristics of the fluctuating trough. A peak is also seen at 51.5 days though it is above the $95 \%$ significance level only at $85^{\circ} \mathrm{E}$. It should be interpreted with some caution since the length of the data is only 2 cycles.

A smoother spectrum may be obtained by the maximum entropy method (MEM). We first standardize the variables by considering

$$
\eta=\frac{y-\bar{y}}{\sigma_{y}},
$$

where $y$ is the latitudinal position (deg.) of the trough on any day and $\bar{y}$ and $\sigma_{y}$ its mean value and standard deviation evaluated over the whole data stretch ( $=103$ days). Associated with MEM is a parameter called its order, which Press et al (1986, p. 433) recommend should be "a few times the number of sharp spectral features that one desires it to fit". Keeping the results of figures 4 and 5 in mind, we have first tried order $M=15$. The spectra are seen to be smoother than the FFT results. At $M=20$ the sharp spectral peak at period $T=7$ days is already split, suggesting that increasing the order 


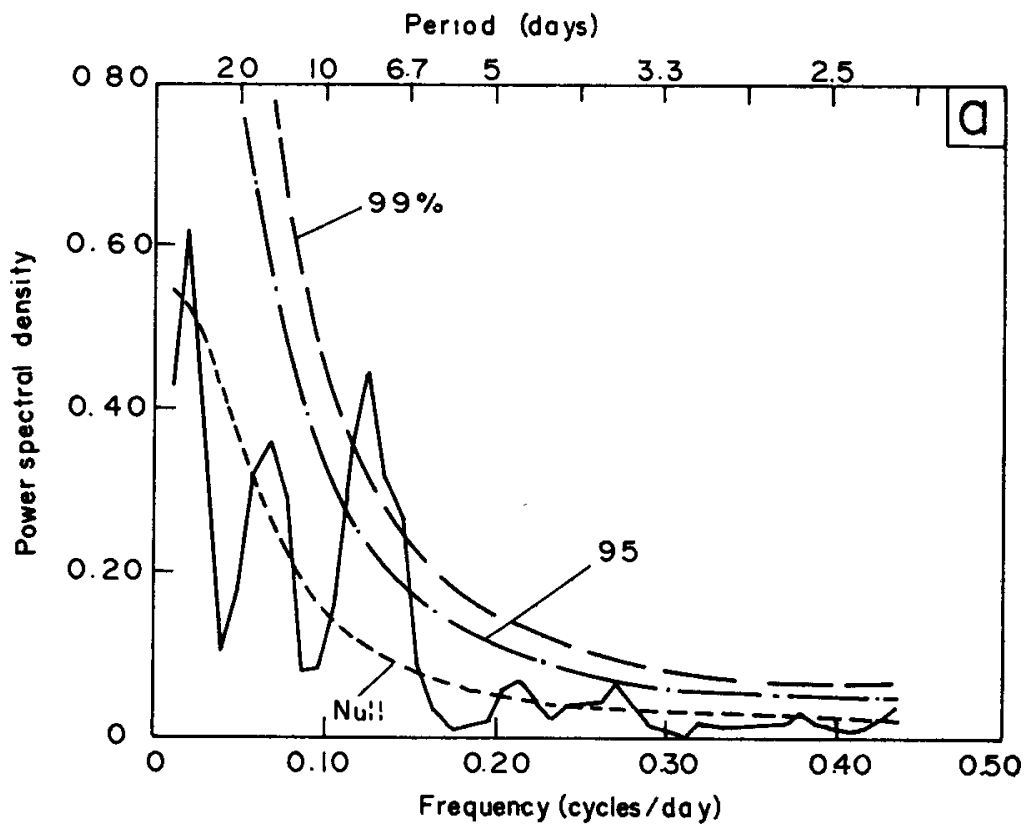

Figure 4(a). Power spectral estimates with confidence limits at $79^{\circ} \mathrm{E}$ (with smoothing).

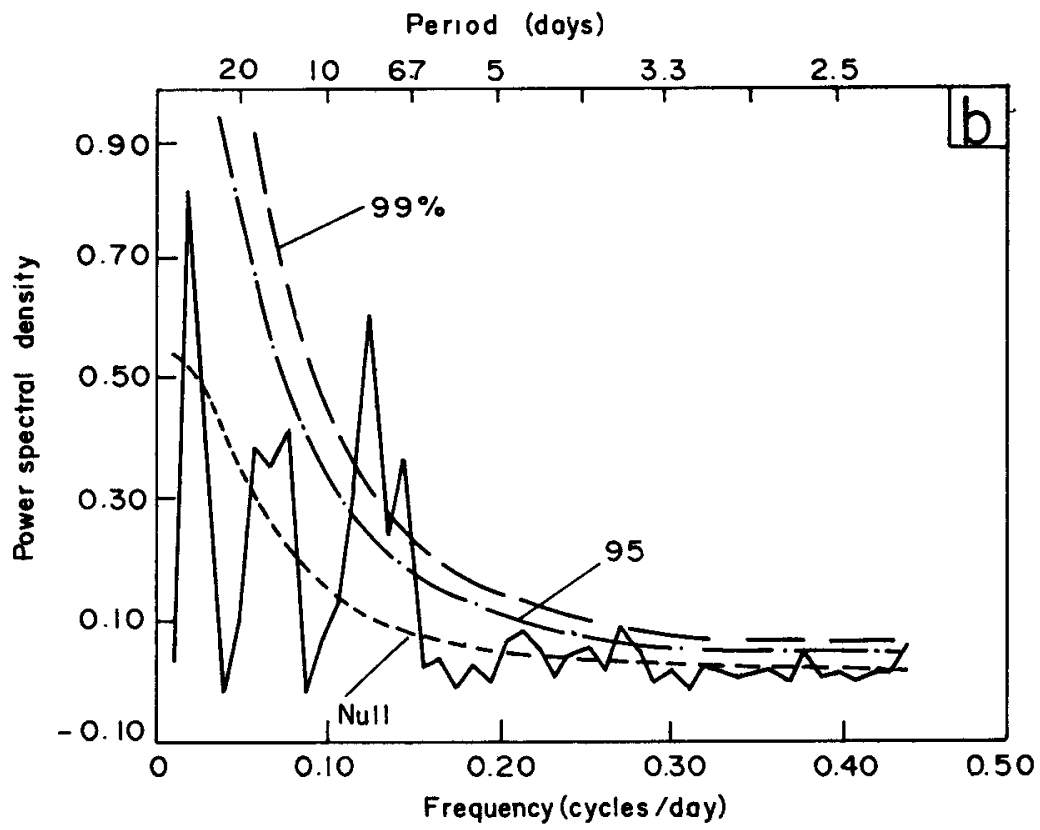

Figure 4(b). Power spectral estimates with confidence limits at $79^{\circ} \mathrm{E}$ (without smoothing). 


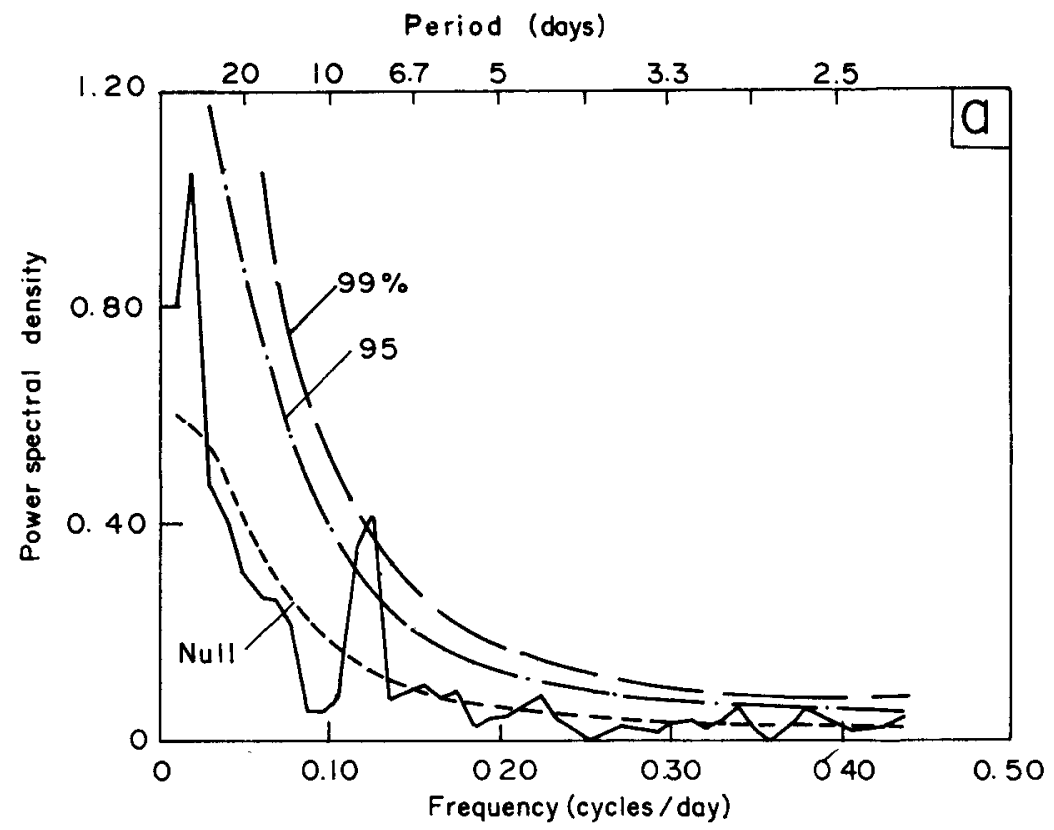

Figure 5(a). Power spectral estimates with confidence limits at $85^{\circ} \mathrm{E}$ (with smoothing).

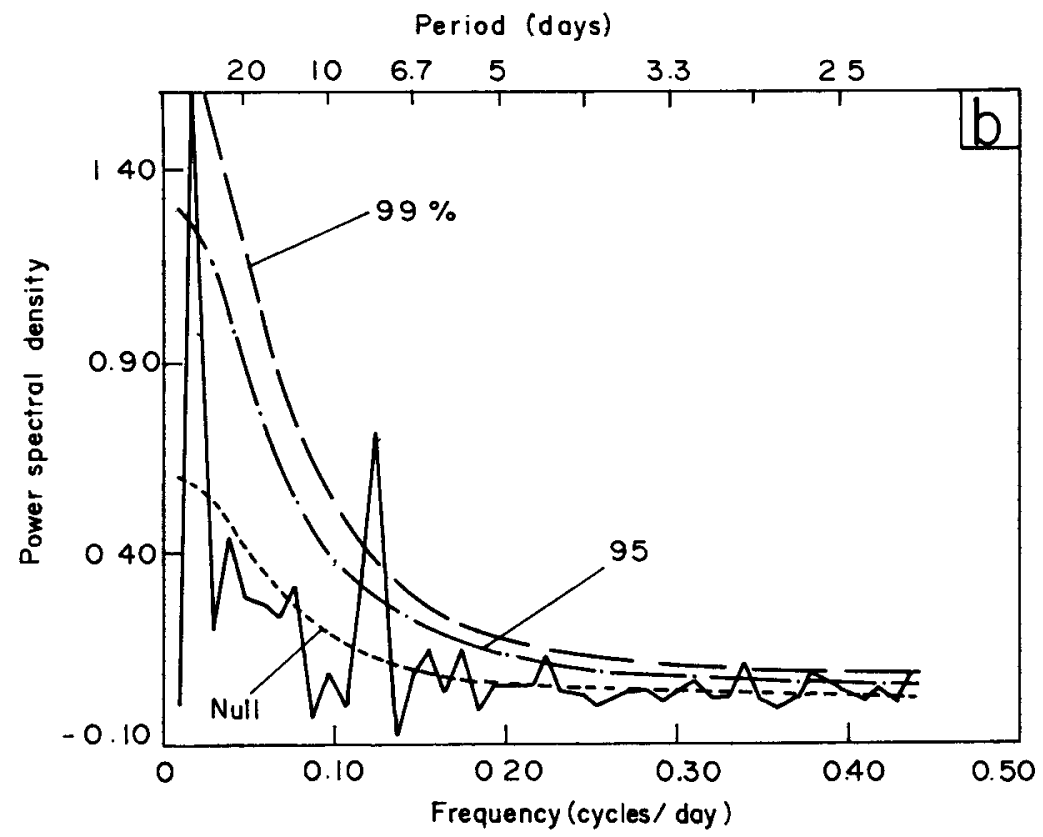

Figure 5(b). Power spectral estimates with confidence limits at $85^{\circ} \mathrm{E}$ (without smoothing). 
further would lead to spurious spectral peaks, as noted by Press et al. However, at $M=40$, a new peak appears at $T=40$ days, but this should again be viewed with caution, as there would be less than 3 cycles of this period in the data stretch examined here.

In the light of this discussion the spectrum evaluated with $M=15$ appears most appropriate, but results with $M=15,20$ and 25 are all shown for both the selected longitudes (figures 6 and 7). In these spectra two peaks viz., one at 7.3 days and another at 14.9 days stand out clearly.

An interesting feature of these spectra is that the peaks at the higher frequencies are more prominent at $85^{\circ} \mathrm{E}$ longitude than at $79^{\circ} \mathrm{E}$, and occur at nearly the same frequencies in both methods.

To study the meteorological significance of these periods, we note that, during the monsoon, periods of clear days alternate with days of disturbed weather due to synoptic

Table 3. Prominent spectral peaks in fluctuations of monsoon trough position.

\begin{tabular}{lcc}
\hline Longitudes deg. (East) & Periods (days) & Confidence level (\%) \\
\hline \multirow{3}{*}{79} & $7 \cdot 7$ & 99 \\
& $3 \cdot 7$ & 95 \\
$2 \cdot 7$ & 95 \\
$51 \cdot 5$ & $>75$ \\
& $7 \cdot 7$ & 99 \\
& 2.9 & 99 \\
85 & $2 \cdot 6$ & 99 \\
& 4.5 & 95 \\
& 51.5 & $>95$
\end{tabular}

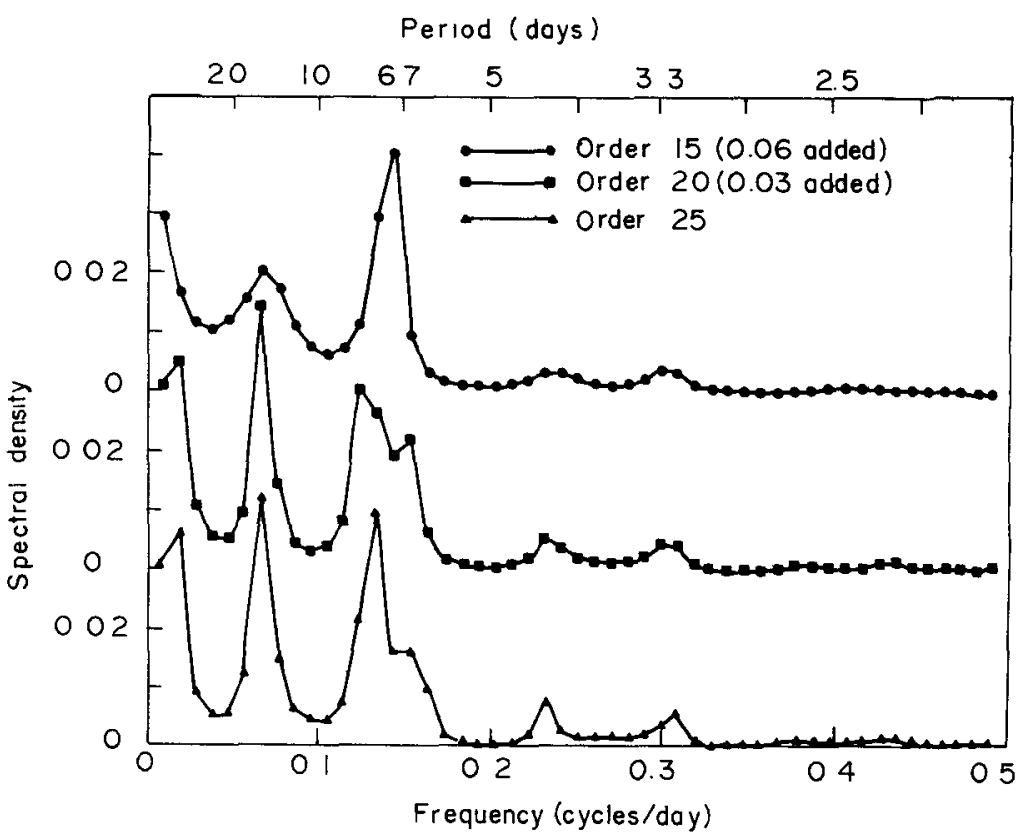

Figure 6. Power spectral estimates using MEM at $79^{\circ} \mathrm{E}$. 


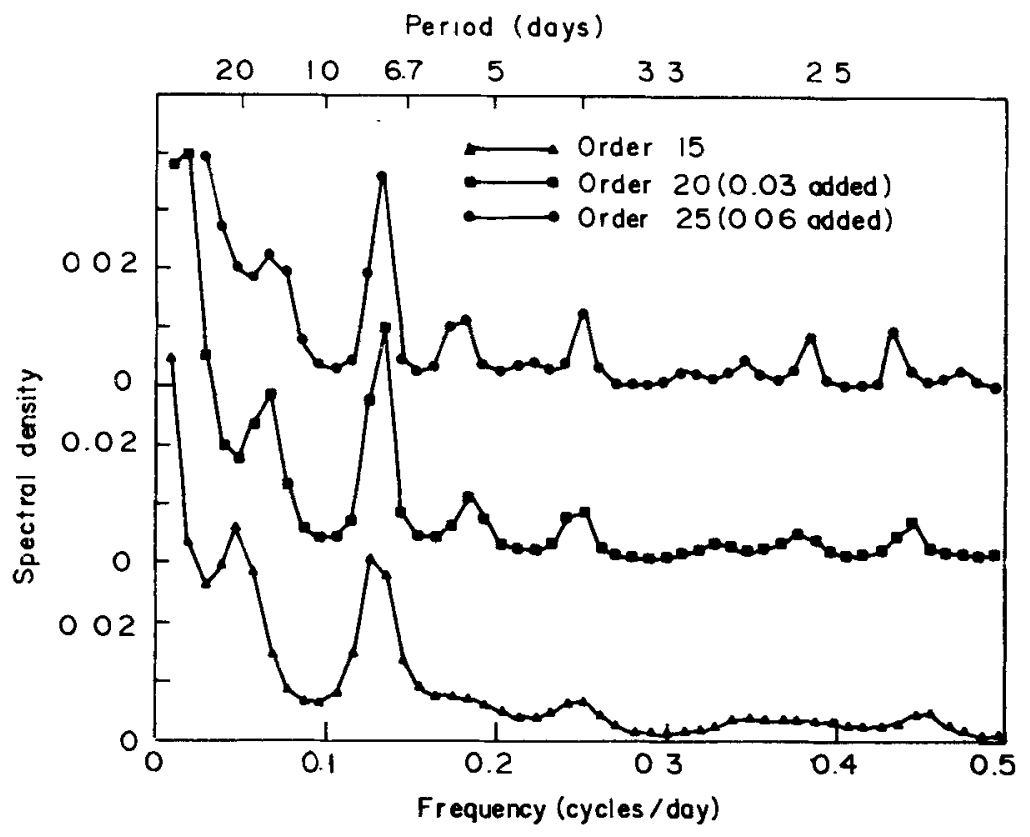

Figure 7. Power spectral estimates using MEM at $85^{\circ} \mathrm{E}$.

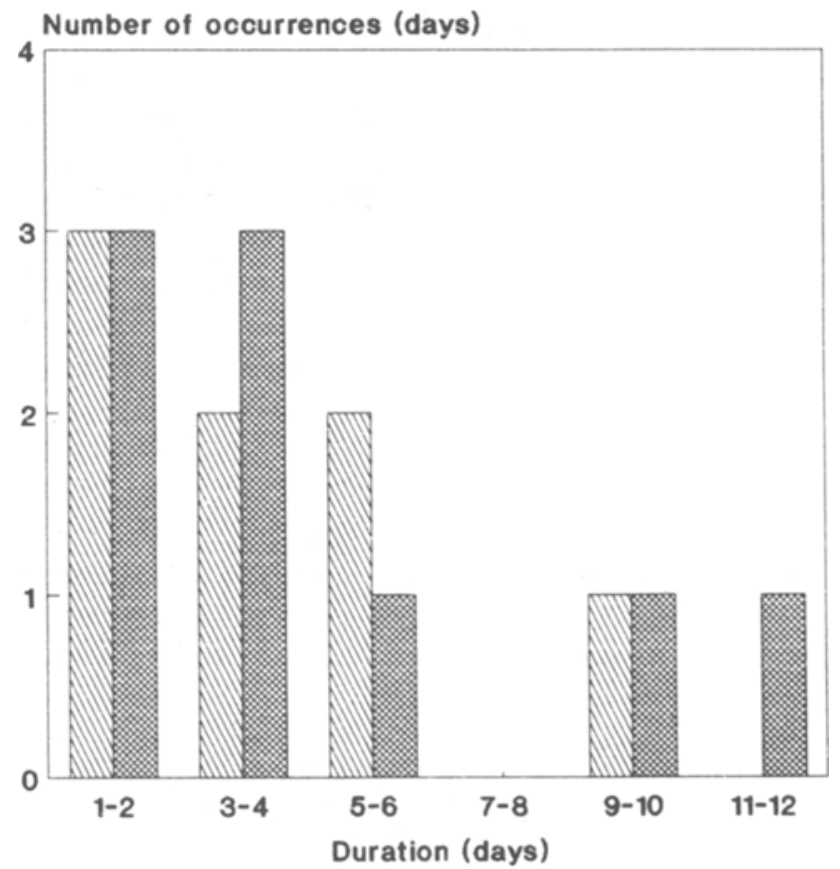

\section{Weather systems Clear days}

Figure 8. Frequency distribution of the life span of synoptic system or period of clear days. 


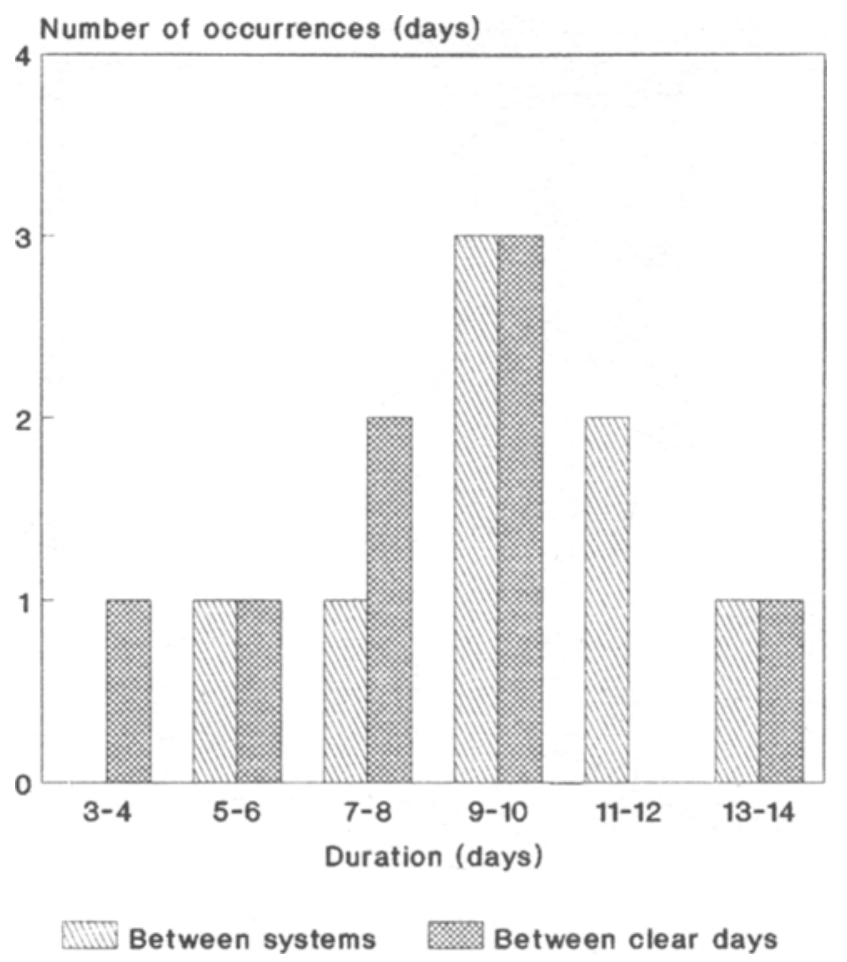

Figure 9. Interval between synoptic systems/stretch of clear days.

systems. The frequency distributions of the life of such weather systems and the duration of periods of clear days are shown in figure 8 . It can be noted that the duration of such synoptic systems or clear periods is around 3 days. This correlates with the spectral peaks at 2.7 and 3 days in figure 5. The reason that these high frequency peaks are seen less prominently at $79^{\circ} \mathrm{E}$ longitude could be that most systems weaken considerably as they penetrate inland. (The available moisture is much less on land when compared to the sea.) The weather systems usually last for a period of about 3 days as can be seen from figure 8 , followed by a similar period of dry days. The time interval between one such system and the next is shown in figure 9. The mode is around 9 days. This correlates well with the peak at 7.7 days in the spectra. The bi-weekly peak mentioned by Krishnamurti and Bhalme (1976) is seen only in the MEM spectra, and is more prominent at $79^{\circ} \mathrm{E}$. There is evidence of a peak at 40-50 days in some of the spectra, and although their statistical significance is low because of the short record length (only 3 periods or less), they are consistent with the occurrence of the well-known 40-day mode (e.g., Sikka and Gadgil 1980).

\section{Conclusions}

The monsoon trough positions during the MONTBLEX-90 period show a highly skewed distribution, with a mode well north of the mean. Because of this skewness one needs to be cautious in defining a 'normal' position for the trough.

Hidden periodicities are sought in the time series of trough position by computing spectral densities using two different methods. Both methods show peaks around 7 to 
8 days, and 2 days and 3 days, the latter being more prominent at $85^{\circ} \mathrm{E}$ longitude. MEM shows a period around 16 days as well. Both methods suggest there might be a peak around 40-50 days.

The 1990 season was characterized by the absence of any true break in the monsoon (Srivastav 1995), so to obtain a complete picture of the statistics of the trough some other years also need to be studied. Such a study is now on hand.

\section{Acknowledgements}

We thank Dr P V Joseph, Prof S Gadgil and Dr D R Sikka for their helpful comments on an earlier version of this manuscript. This work was supported by a grant from the Department of Science and Technology, Government of India.

\section{References}

Blackman R B and Tukey J W 1958 The measurement of power spectra. (New York: Dover Publications) Krishnamurty T N and Bhalme H N 1976 Oscillations of a monsoon system. Part I: Observational aspects; J. Atmos. Sci. 33 1937-1954

MacDonald G J 1989 Spectral analysis of time series generated by nonlinear processes; Rev. Geophys. 27 449-469

Paul D K and Sikka D R 1976 Extended range forecasting-categorization of weather charts, Part I: Monsoon sea level pressure field. Project report no: ERF/1, 34 pp. (Indian Institute of Tropical Meteorology, Pune)

Press W H, Flannery B P, Teukolsky S A and Vetterling W T 1986 Numerical Recipes. (Cambridge University Press)

Rao Y P 1976 The southwest monsoon. (India Meteorological Department)

Sikka D R and Gadgil S 1980 On the maximum cloud zone and the ITCZ over Indian longitudes during the southwest monsoon; Mon, Weather Rev. 108 1840-1853

Sikka D R and Narasimha R 1995 Genesis of the monsoon trough boundary layer experiment (MONTBLEX); Proc. Indian Acad. Scl. (Earth Planet. Sci.) 104 157-187

Srinivasan V and Ramakrishnan A R 1970 Location of the monsoon trough over India in the lower troposphere during July-August. Proc. Symp. Tropıcal Meteorology; Am. Meteorol. Soc. 2-11 (University of Hawaii, Honolulu)

Srivastav S K 1995 Synoptic meteorological observations and weather conditions during MONTBLEX-90; Proc. Indian Acad. Sci. (Earth Planet. Sci.) 105 189-220

Tukey J W 1950 The sampling theory of power spectrum estimates. Symposium on Applications of autocorrelation analysis to physical problems; U.S. Office of Naval Research NAVEXOS-P-735 pp. 47-67 (Washington D.C.)

WMO 1966 Some methods in climatological analysis; WMO Tech. Note No. 8153 pp. WMO (Geneva) 